\title{
Uso de geotecnologias para determinação de áreas de preservação permanente em trecho da Sub-bacia do Rio Piranhas, Semiárido, Brasil
}

Use of geotechnologies for determination of permanent preservation areas in a section of the Piranhas Sub-basin, Semiarid, Brazil

Uso de geotecnologías para determinar áreas de preservación permanente en una sección de la Subcuenca del Río Piranhas, Semiárido, Brasil

Recebido: 01/09/2021 | Revisado: 08/09/2021 | Aceito: 13/09/2021 | Publicado: 15/09/2021

\author{
Gabriela Gomes Ramos \\ ORCID: https://orcid.org/0000-0002-2028-1503 \\ Universidade Federal de Campina Grande, Brasil \\ E-mail: gabiengflorestal@gmail.com \\ Denize Monteiro dos Anjos \\ ORCID: https://orcid.org/0000-0003-3856-0102 \\ Universidade Federal da Paraíba, Brasil \\ E-mail: denizegeo16@gmail.com \\ Joedla Rodrigues de Lima \\ ORCID: https://orcid.org/0000-0001-6617-2858 \\ Universidade Federal de Campina Grande, Brasil \\ E-mail: joedlalima@yahoo.com.br \\ Géssica dos Santos Vasconcelos \\ ORCID: https://orcid.org/0000-0002-9262-6793 \\ Universidade Federal de Campina Grande, Brasil \\ E-mail: gsvasconc@gmail.com \\ Isabella Rocha Ribeiro \\ ORCID: https://orcid.org/0000-0002-1666-6785 \\ Universidade Federal de Campina Grande, Brasil \\ E-mail: isabellaengflorestal@gmail.com
}

\begin{abstract}
Resumo
A delimitação de habitats geomorfológicos proporciona a identificação de áreas com maior relevância ecológica. O objetivo deste trabalho foi delimitar, utilizando geotecnologias, a rede de drenagem e fragmentos da mata ciliar da subbacia do alto Piranhas/PB. O trabalho foi desenvolvido em trechos do rio Piranhas, iniciando no açúde de São Gonçalo, próximo ao município de Sousa, Paraíba, e seguindo cerca de $20 \mathrm{~km}$ a direção da nascente do rio, localizada no município de Bonito de Santa Fé. Foram utilizadas as imagens dos satélites Sentinel 2 B, e a composição de RGB (vegetação, corpos hídricos e solo) foi a RGB: 4 - 3 - 2. As Áreas de Preservação Permanente da sub-bacia foram desenhadas utilizando a ferramenta de delimitação (Buffer). Os layouts dos mapas foram confeccionados no software QGIS versão 2.18.1. Os dados cartográficos gerados se deram no sistema de referência datum SIRGAS2000 e em coordenadas geográficas. Foram identificados locais em que a faixa destinada à preservação sofria degradação. Os impactos ambientais ficam mais evidentes ao modo que se afasta do Açude de São Gonçalo, pondo em evidência a supressão da vegetação nativa, substituída pela pequena agricultura, pastagens e construção de moradias. Os pontos 1 e 3 se encontravam com o maior número de indivíduos de vegetação aberta e densa, e os pontos 2 e 4 com grandes áreas de cultivo e pastagens. Há uma escassez de vegetação nativa, pelo uso inadequado do solo em alguns pontos da Área de Preservação Permanente, em contraposição ao que rege a legislação.
\end{abstract}

Palavras-chave: Delimitação; Sensoriamento remoto; Mata ciliar.

\begin{abstract}
The delimitation of geomorphological habitats provides the identification of areas with greater ecological relevance. The objective of this work was to define, using geotechnologies, the drainage network and fragments of the riparian forest in the upper Piranhas/PB sub-basin. The work was developed in stretches of the Piranhas River, starting at the São Gonçalo dam, close to the municipality of Sousa, Paraíba and following about 20km in the direction of the source of the river, located in the municipality of Bonito de Santa Fé. The images from the Sentinel 2 B satellites were used, the RGB composition (vegetation, water bodies and soil) was RGB: 4 - 3 - 2. The areas of permanent preservation of the sub-basin were designed, using the delimitation tool (Buffer). The map layouts were made using the QGIS software version 2.18.1. The cartographic data generated was given in the SIRGAS2000 datum reference system and in geographic coordinates. Locations were identified in which the strip intended for preservation suffered degradation, the
\end{abstract}


environmental impacts are more evident as it moves away from the São Gonçalo Dam, in evidence the native vegetation suppression, replaced by small agriculture, pastures and housing construction. Points 1 and 3 met the largest number of individuals with open and dense vegetation, and points 2 and 4 with large areas of cultivation and pastures. There is a shortage of native vegetation due to inadequate use of the soil in some points of the Permanent Preservation Area in contrast to what is governed by the legislation.

Keywords: Delimitation; Remote sensing; Riparian forest.

\section{Resumen}

La delimitación de hábitats geomorfológicos proporciona la identificación de áreas con mayor relevancia ecológica. El objetivo de este trabajo fue delimitar, mediante geotecnologías, la red de drenaje y fragmentos de bosque de ribera en la subcuenca alta Pirañas / PB. La obra se desarrolló a lo largo de tramos del río Pirañas, comenzando en el embalse São Gonçalo, cerca del municipio de Sousa, Paraíba, y siguiendo aproximadamente $20 \mathrm{~km}$ en dirección al nacimiento del río, ubicado en el municipio de Bonito de Santa Fé. de los satélites Sentinel 2 B, y la composición RGB (vegetación, cuerpos de agua y suelo) fue RGB: 4 - 3 - 2. Las Áreas de Preservación Permanente de la subcuenca se dibujaron utilizando la herramienta de delimitación (Buffer). Los diseños de mapas se realizaron utilizando el software QGIS versión 2.18.1. Los datos cartográficos generados se dieron en el sistema de referencia datum SIRGAS2000 y en coordenadas geográficas. Se identificaron lugares donde la franja destinada a la preservación sufrió degradación. Los impactos ambientales se hacen más evidentes a medida que se aleja de la presa São Gonçalo, destacando la supresión de la vegetación nativa, reemplazada por la agricultura a pequeña escala, los pastos y la construcción de viviendas. Los puntos 1 y 3 tenían el mayor número de individuos con vegetación abierta y densa, y los puntos 2 y 4 tenían grandes áreas de cultivo y pastos. Existe una escasez de vegetación nativa, debido al inadecuado uso del suelo en algunos puntos del Área de Conservación Permanente, en contraste con lo que se rige por la legislación.

Palabras clave: Delimitación; Teledetección; Bosque de ribera.

\section{Introdução}

A Política Nacional dos Recursos Hídricos (PNRH) apresenta, como um dos seus objetivos, a utilização racional e integrada dos recursos hídricos de forma sustentável e toma, como unidade de gestão, a bacia hidrográfica, para, inclusive, reduzir ou minimizar os impactos ambientais causados nos ecossistemas pelas ações antrópicas (Brasil, 1997).

Segundo Araújo (2018), muitas vezes, essas ações refletem no desaparecimento de espécies devido à exploração desordenada e falta de práticas adequadas de manejo e reflorestamento, o que acaba modificando a paisagem.

A dinâmica das paisagens é bem mais complexa devido a sua heterogeneidade e esta vem sendo alterada cada vez mais pelas ações humanas, em decorrência da grande exploração dos recursos naturais. Segundo Oliveira et al. (2010), a caracterização da paisagem e o monitoramento das regiões úmidas é de grande importância para a gestão de recursos naturais. Dessa forma, o sensoriamento remoto vem sendo amplamente utilizado no monitoramento espaço-temporal dos recursos naturais.

No semiárido brasileiro não é diferente, ocorrem muitas práticas de exploração, principalmente em ambientes inundados, as chamadas matas ciliares. Uma das principais práticas é a substituição da vegetação nativa para o uso de atividades agrícolas, o que deixa o solo desprotegido e propenso à erosão, causando o assoreamento e eutrofização de mananciais e diminuição da calha dos rios (Valle Junior et al., 2011).

Segundo Araújo et al. (2018), esses ambientes são de grande importância por serem responsáveis pelo equilíbrio ecológico de determinadas regiões, servindo como corredor ecológico de disseminação de espécies pelo vento, água e animais, além de serem protetores e mantedores da qualidade da água e do solo.

A distribuição de água no semiárido brasileiro acaba por apresentar uma situação especial devido às variações climáticas existentes na região. A geologia determina as condições de esgotamento rápido da água no solo, atribuindo aos corpos hídricos (rios, açudes) uma característica muito presente nos municípios da região (Macedo, 2014).

Desse modo, encontra-se a bacia hidrográfica do Rio Piranhas-Açu, localizada entre os estados da Paraíba e Rio Grande do Norte, inserida no semiárido nordestino. Nessa região, as principais precipitações se concentram nos meses de fevereiro a abril. A geomorfologia está associada aos terrenos cristalinos, os solos são jovens, caracterizados, em geral, por serem rasos e 
com baixa capacidade de armazenamento de água, justificando a característica predominante dos rios da região, que são intermitentes (ANA, 2016).

Na unidade de planejamento hidrológico do Alto Piranhas, precisamente localizado no distrito de São Gonçalo, está situado o açude São Gonçalo, responsável por abastecer os seus municípios próximos, como Sousa, Cajazeiras, Marizópolis, além do uso em cultivos, em perímetros irrigados, sendo as principais culturas a de banana e a de coco (ANA, 2016).

Diante disso, o objetivo deste trabalho foi delimitar utilizando geotecnologias, a rede de drenagem e fragmentos da mata ciliar da sub-bacia do Alto Piranhas/PB.

\section{Metodologia}

O trabalho foi desenvolvido em trechos do rio Piranhas, precisamente em fragmentos da região hidrográfica do Alto Piranhas, iniciando no açude São Gonçalo, localizado no distrito de São Gonçalo, próximo ao município de Sousa, no estado da Paraíba, e seguindo cerca de $20 \mathrm{~km}$ a direção da nascente do Rio Piranhas, localizada no município de Bonito de Santa Fé.

A sub-bacia do rio Piranhas possui área total de $2.562 \mathrm{~km}^{2}$, abrangendo 19 municípios paraibanos, com clima As, com verão seco, segundo a classificação de Köppen, com temperatura variando entre $25^{\circ} \mathrm{C}$ a $28^{\circ} \mathrm{C}$, estando inserida na depressão sertaneja setentrional. Apresenta uma extensa planície baixa, com relevo suave-ondulado (Figura 1) (Alvares et al., 2014; ANA, 2016).

Figura 1 - Localização da região hidrográfica do Alto Piranhas, Paraíba. Imagem Google Earth, Data: 08/02/2018.

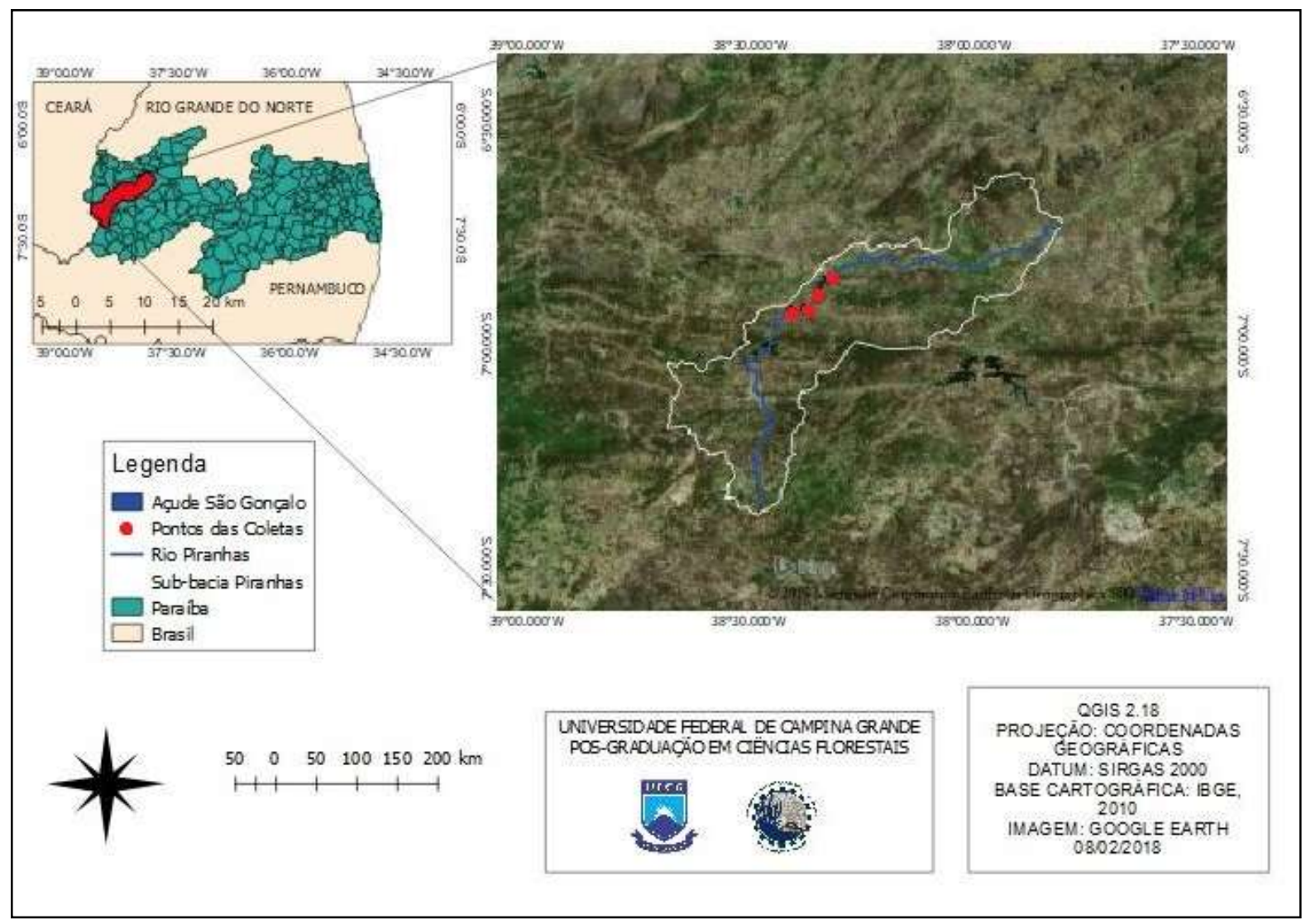

Fonte: Ramos et al., (2021).

Segundo ANA (2016), os solos da região do Alto Piranhas se caracterizam como Luvissolos Crômico, Planossolos Hidromórfico, Neossolos Litólico e Argissolos Vermelho-Amarelo, uma vegetação hiperxerófila com espécies caducifólias, 
precipitação média anual de $800 \mathrm{~mm}$, sendo distribuídas entre os meses de fevereiro a abril, com elevada evapotranspiração, com o valor médio anual de $2.937 \mathrm{~mm}$, com vegetação classificada como Caatinga floresta estacional e formações pioneiras com influência fluviomarinha (Farias, 2004; Silva et al., 2013; ANA, 2016).

O açude de São Gonçalo está situado na unidade de planejamento hidrológico do Alto Piranhas. Em 1889, foram realizados os primeiros estudos para a construção do Açude, entretanto as obras só foram iniciadas em 1921, sendo sua inauguração oficial em 1936, e, em 1973, foi inaugurado o perímetro irrigado de São Gonçalo (Silva, Braga A. \& Braga C., 2011). No presente momento obras no açude são realizadas para manutenção e melhoria do mesmo.

O açude São Gonçalo destina-se a fornecer água para irrigar 4.104 ha, abastecendo o perímetro irrigado das várzeas de Sousa, situado em terrenos de escudos cristalinos. Seus sistemas de irrigação principais são o pivô central, irrigação superficial e microaspersão. As principais culturas agrícolas utilizadas na região são o milho, feijão e coco (Lima, Barbosa \& Dantas Neto, 1998; ANA, 2016).

Segundo Silva, Braga A. e Braga C. (2011), o perímetro irrigado de São Gonçalo é formado principalmente por fruticultura, com capacidade de demanda hídrica de 44,6 milhões de $\mathrm{m}^{3}$, com áreas de vegetação nativa e agricultura de sequeiro (Silva et al., 2013).

Inicialmente delimitou-se o trecho determinado entre o açude São Gonçalo e a respectiva rede de drenagem à montante, utilizando a ferramenta buffer no software QGIS versão 2.18.21, de largura de 50m, respeitando a calha do rio e obedecendo à Lei de $\mathrm{n}^{\mathrm{o}}$ 12.651, de 25 de maio de 2012, que determina uma área de preservação de 50 metros, para os cursos d'água que tenham de 10 a 50 metros de largura.

Em relação ao reservatório, considerou-se a redação dada pela Lei nº 12.727/2012, no Art. $5^{\circ}$, quando afirma que, na implantação de reservatório d'água artificial destinado à geração de energia ou abastecimento público, é obrigatória a aquisição de Áreas de Preservação Permanente criadas em seu entorno, observando-se a faixa mínima de 30 (trinta) metros e máxima de 100 (cem) metros em área rural, e a faixa mínima de 15 (quinze) metros e máxima de 30 (trinta) metros em área urbana.

Após a delimitação, realizou-se o recorte nas imagens utilizadas para classificação do uso e cobertura da terra das áreas de preservação dos perímetros urbano e rural, utilizando as metodologias de Mendes (2018), Victoria, Hott \& Miranda (2008).

Um fragmento de Áreas de Preservação Permanente da sub-bacia foi desenhada utilizando a ferramenta de delimitação (Buffer), construído a partir de um polígono entre os elementos geométricos que representaram o curso d'água, com as larguras determinadas anteriormente.

As imagens dos satélites Sentinel 2 B são disponibilizadas pelo U. S. Geological Survey (USGS) e foram adquiridas no endereço eletrônico http://earthexplorer.usgs.gov/. As imagens possuem resolução espacial de $10 \mathrm{~m}$ nas bandas do visível ao infravermelho. Nesta pesquisa, utilizou-se uma cena do dia 20/02/2018, com órbita ponto de T24MWT.

A composição para identificar os alvos (vegetação, corpos hídricos e solo) foi a RGB: 4 -3 - 2. A classificação foi concebida pelo método de segmentação de imagens, consiste na divisão ou separação da imagem em regiões de atributos similares ou de mesmas características (Jensen, 2009).

O procedimento foi realizado pelo algoritmo do Orfeo Toolbox, instalado no QGIS vs 2.18.1. A classificação teve o intuito de qualificar os usos e ocupações da Área de Preservação Permanente ao longo do trecho estudado.

Através das coletas realizadas na área, foi possível determinar o uso e ocupação da Área de Preservação Permanente.

Efetivada a classificação, foram gerados "shapifile" de classes de uso e cobertura da terra. Para comprovação e controle das classes geradas pela classificação, verificou-se em campo as áreas correspondentes ao longo do rio Piranhas e no Reservatório São Gonçalo.

A partir da delimitação da Área de Preservação Permanente (mata ciliar), foram produzidos mapas temáticos que permitem observar as principais atividades realizadas na área. Os layouts dos mapas foram confeccionados no software QGIS 
versão 2.18.1. Todos os dados cartográficos gerados estão no sistema de referência datum SIRGAS2000 e em coordenadas geográficas.

\section{Resultados e Discussão}

De acordo com os resultados dos mapeamentos realizados, os quais tiveram como base as imagens de satélites, a área estudada apresenta diversidade do uso e ocupação, como se observa na Figura 2.

Figura 2 - Mapa de classificação da Área de Preservação Permanente (APP) do Açude São Gonçalo e trecho do Rio Piranhas. Imagem Sentinel 2B, Data: 28/06/2018, composição RGB(4-3-2). Paraíba. 2020.

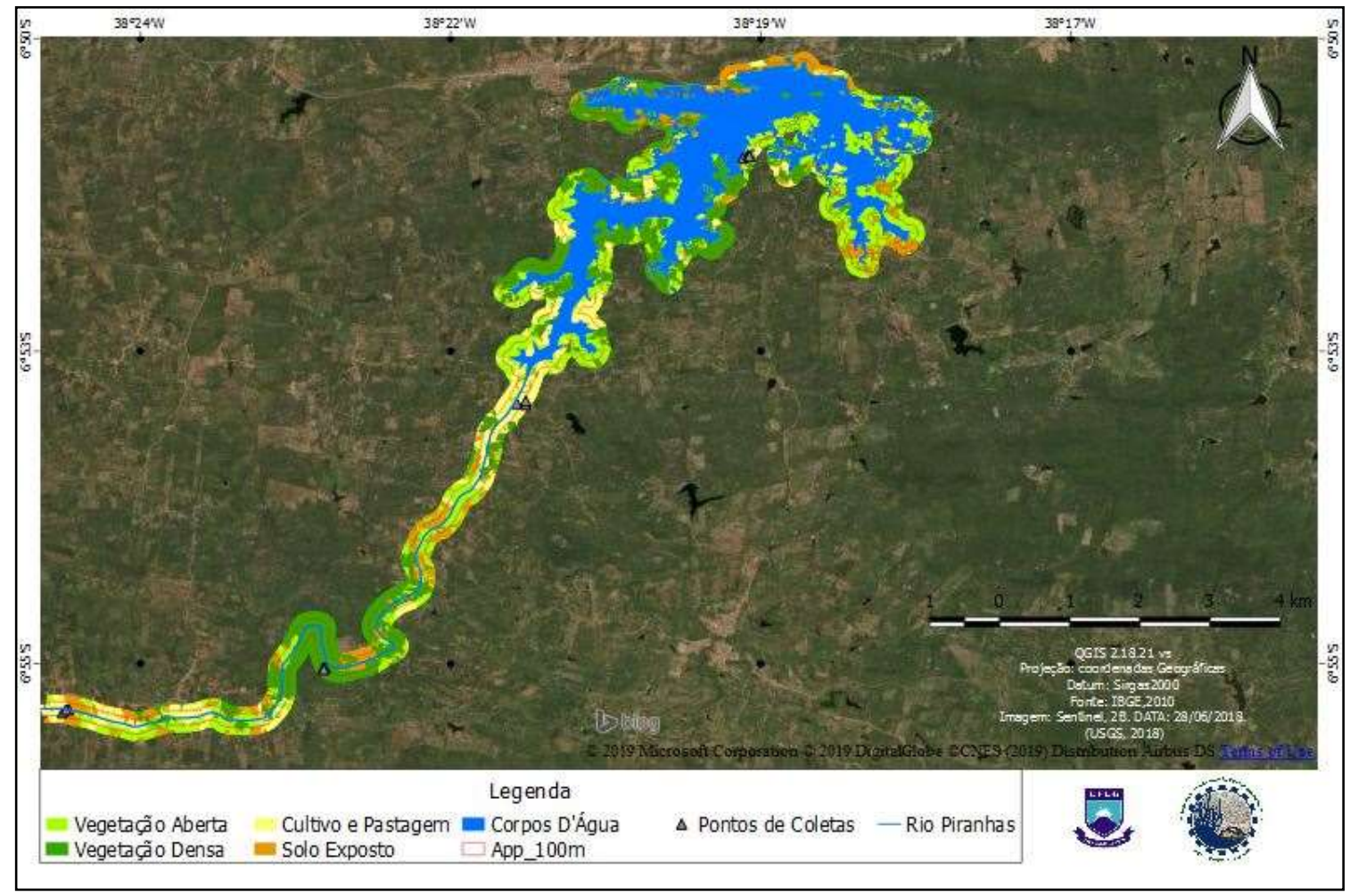

Fonte: Ramos et al., (2021).

A classificação foi dividida em vegetação aberta, vegetação densa, cultivo e pastagem e solo exposto. Dentre essas, destacam-se, no entorno do açude São Gonçalo, a vegetação densa e a aberta.

Em observação in loco, incluindo diálogo com os residentes da zona rural, próximo ao açude São Gonçalo, os mesmos relatam que não têm a agricultura familiar como sua principal fonte de renda, mas sim de empregos nos municípios próximos, como Sousa e Cajazeiras, o que justifica a menor utilização da terra e, portanto, o maior índice de vegetação densa e aberta.

Siqueira et al. (2018) destacam que, para a garantir sua sobrevivência e de seus familiares, muitos agricultores que viviam da agricultura irrigada optam por procurar emprego nas cidades vizinhas e até mesmo em outros estados, devido aos grandes problemas ambientais causados à biota do solo e à fauna, decorrentes da contaminação de produtos químicos. Diminuise a produtividade e os agricultores acabam optando por outras atividades ou atividades complementares.

Quando comparados com o Código Florestal (12.651/2012), pode-se observar que muitas áreas estão sendo utilizadas indevidamente, para a agricultura, pecuária, pastagem e construções de moradias, sendo que deveriam ser áreas protegidas para a manutenção da biodiversidade desses ecossistemas. Cabe às autoridades competentes tomar medidas emergentes para o cumprimento da legislação. 
Haas et al. (2018) encontraram as mesmas características da mata ciliar em sua delimitação da sub-bacia do lajeado pardo, noroeste do RS. A delimitação de APPs é de extrema importância para o diagnóstico do potencial risco natural e pelo uso e ocupação do solo, que afetam toda a bacia hidrográfica e os seus recursos utilizados no manejo de bacias.

Segundo Silva et al. (2011), o que causa a ausência da mata ciliar é o uso das áreas naturais para a agricultura, pecuária, loteamentos e construções de hidroelétricas, o que contribui para a redução da vegetação.

Calheiros et al. (2004) destacam as principais funções da mata ciliar, como manter o equilíbrio hidrológico através da estabilização das margens dos rios, controle do aporte de nutrientes, filtragem, controle da temperatura dos ecossistemas aquáticos e barragem contra o carregamento de sedimentos, evitando o assoreamento das microbacias hidrográficas.

Foram identificadas as áreas situadas entre os pontos de coleta em que a faixa destinada à preservação sofre degradação, dentre elas, destacam-se os pontos 2 e 4, onde os impactos ambientais ficam mais evidentes ao modo que se afasta do Açude, cujas ações antrópicas destacam-se, a supressão da vegetação nativa, substituída por pequenas agriculturas, pastagens e construção de moradias (Figura 3).

Figura 3 - Mapa de uso e ocupação da Área de Preservação Permanente do Açude São Gonçalo e trecho do Rio Piranhas. Imagem Sentinel 2B, Data: 28/06/2018, composição RGB(4-3-2). Paraíba. 2021.

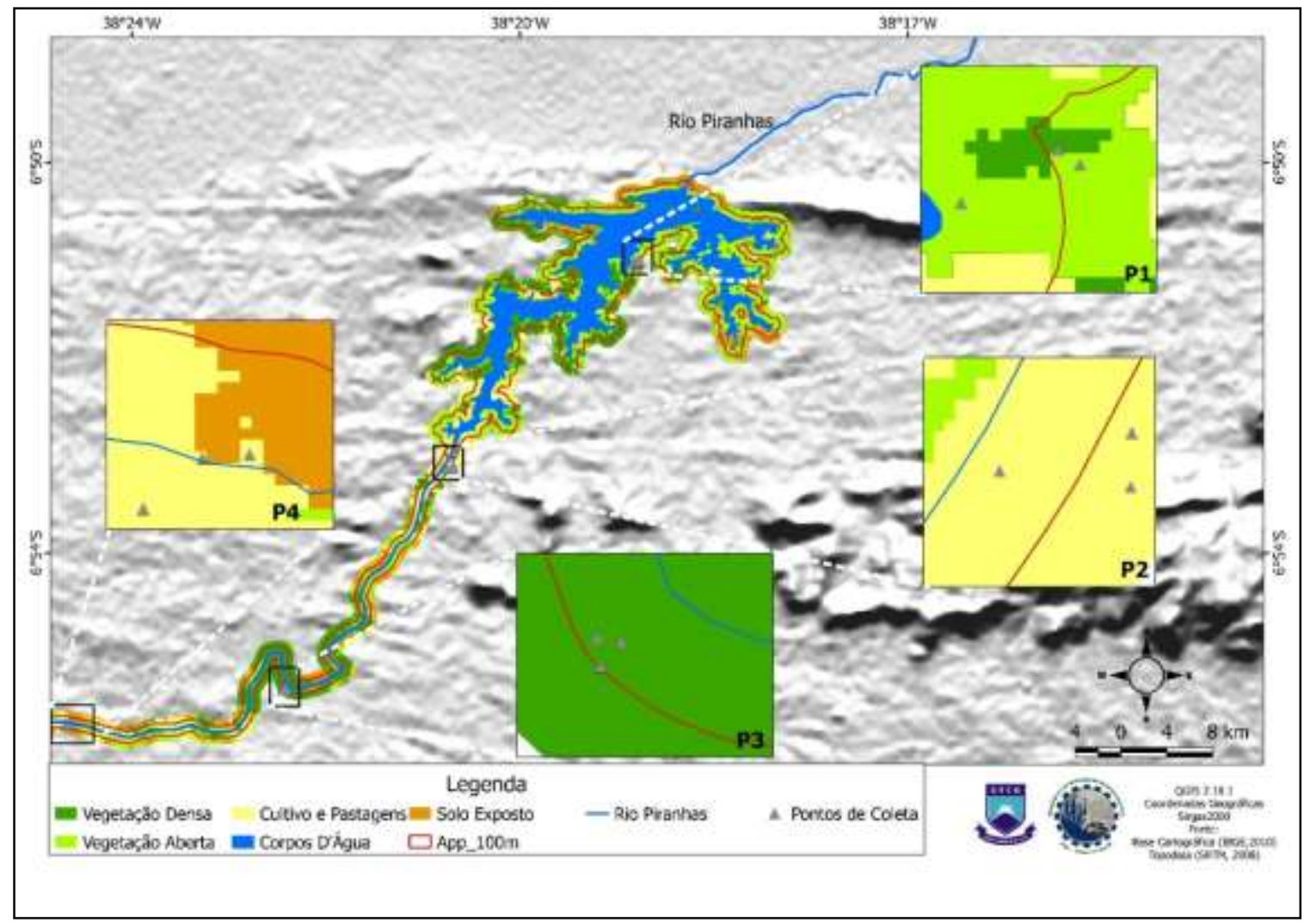

Fonte: Ramos et al., (2021).

Os pontos que se destacaram por possuir uma maior faixa de vegetação foram os pontos 1 e 3, em contraposição aos pontos 2 e 4, que apresentaram fortes áreas de pastagem e cultivos. Quando observada a mata ciliar como um todo, pode-se ver uma faixa de vegetação entre áreas cultivadas, o que leva a crer que essa área ainda permanece com vegetação nativa. Em seu estudo, Zakia et al. (2009) observaram que, enquanto o código florestal determina uma faixa de proteção ao longo dos cursos d'água, as áreas que são de fato importantes para as microbacias se encontram agrupadas de forma diferente. 
Mendes, Reis Filho e Espindola (2019) verificaram que, na APP do Rio Poti, no município de Teresina-PI, prevalece área ocupada por cobertura vegetal com remanescentes de vegetação de Caatinga ocupando uma parte na zona rural e outra na urbana, entretanto há partes em que o solo exposto e áreas edificadas se destacam pelo grande número de ocupação.

Atualmente o código florestal diminuiu os limites dessas faixas de proteção no ano de 2012, deixando as áreas mais vulneráveis (Haas et al., 2018). E, observando-se na Figura 9, verifica-se que existem mais áreas de cultivo e solo exposto juntos do que a vegetação nativa nessas faixas (Figura 4).

Figura 4 - Fisionomias dos pontos estudados nas margens do Rio Piranhas, Paraíba. Imagens registradas nas datas A(22/03/2018), B(23/05/2018), C e D(10/08/2018). Paraíba.2021.

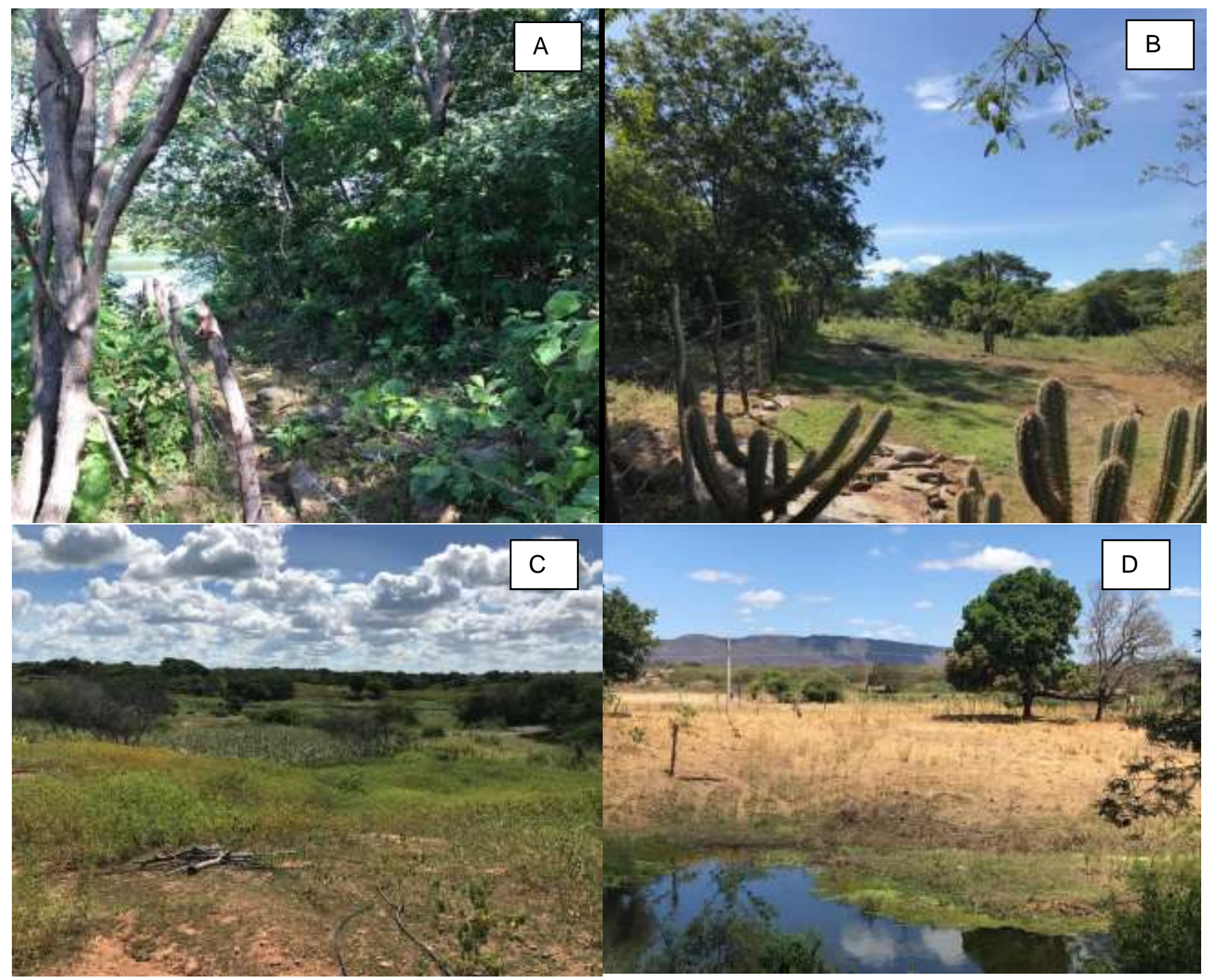

A (24 M 0574867 E 9242180 S 250 M); B (24 M 0571768 E 9238697 S 272 M); C (24 M 0568880 E 9234977 S); D (24 M 0565084 E 9234335 S). Fonte: Ramos et al., (2021).

Nas imagens, pode-se observar: a vegetação densa (A) com um número elevado de indivíduos, sendo eles de pequeno e médio porte; a vegetação aberta (B) representando áreas que estão em fase de restauração por possuírem principalmente espécies pioneiras, como a Mimosa tenuiflora (Willd.) Poir (Jurema Preta), em grande número e cultura de pastagens (C), muitas vezes, pela agricultura familiar. E, em sequência, observam-se áreas extensas de plantações e o Solo Exposto (D), sendo que por 
muitas vezes, a área apresenta estágio avançado de degradação, onde se verifica o alto grau de erosão das margens dos rios e próximos a eles, tornando o rio assoreado, além de retirar a camada mais rica em nutrientes do solo e redução da biodiversidade.

Na Figura 5 destaca-se a localização dos pontos ao longo do rio Piranhas, sendo observadas, com mais clareza, as condições da Área de Preservação Permanente do fragmento estudado.

Figura 5 - Mapa de localização dos pontos 1, 2, 3 e 4 na Área de Preservação Permanente ao longo do Rio Piranhas. Imagem Google Earth, Data: 08/02/2018. Paraíba. 2021.
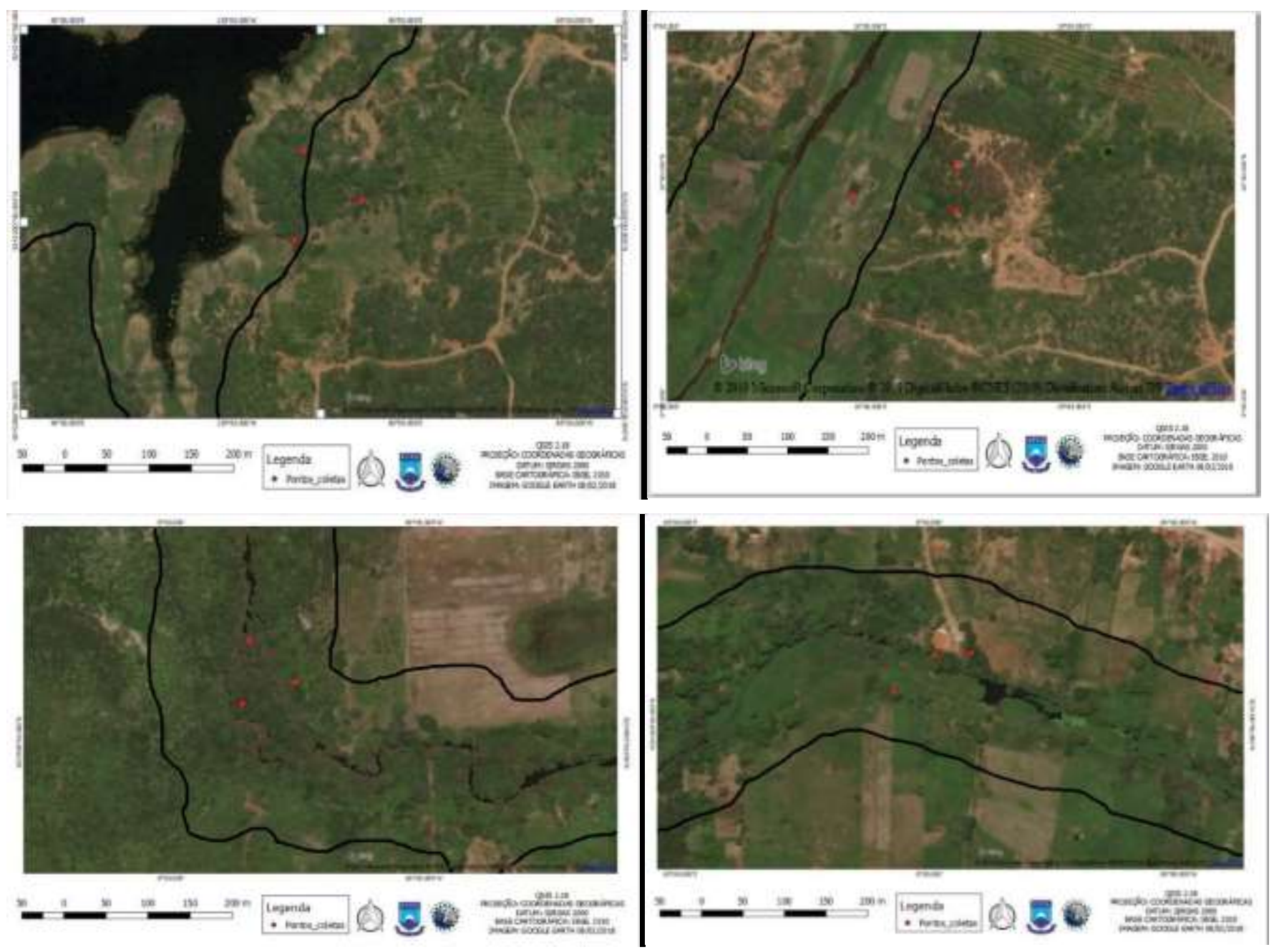

Fonte: Ramos et al., (2021).

O ponto 1 se destacou pelo maior número de indivíduos e pela vegetação densa e bem próxima, o cultivo e as pastagens, além do desmatamento verificado em três pontos de coleta, assim como Nascimento (2018), em sua pesquisa de APP, no rio Piranhas-Açu, na comunidade de Arapuá-Ipanguaçu/ RN, na qual encontrou pouca vegetação e áreas cercadas de bovinos, além da produção agrícola. O referido autor identificou que, em 2018, havia uma boa área com campo de pastagem e de vegetação pouco densa, possivelmente o que é mais encontrado é a produção agrícola irrigada.

O mesmo ocorre ao logo do rio Piranhas, com faixas de perímetros irrigados, com Melo Filho et al. (2019) destacando que o perímetro irrigado produz: coco, maracujá, banana, goiaba, milho, arroz, feijão, algodão herbáceo, capim de corte, entre outras, além da pecuária leiteira e produção de carnes, sendo a captação de água feita do açude de São Gonçalo levada diretamente pelos canais principais, para bombeamento. 
O ponto 2 foi onde mais se observou a interferência de ações antrópicas, pois é quase inexistente a ocorrência de indivíduos da vegetação nativa. Segundo Zakia et al. (2009), os canais intermitentes são de extrema importância para a correta produção do escoamento direto nas microbacias, portanto sua conservação e proteção são fundamentais para a manutenção de sua saúde.

Pode-se observar também o uso inadequado em Área de Preservação Permanente das faixas marginais dos rios, onde se visualizam atividades agrárias, como a pecuária e construções rurais.

Mesquita, Cruz e Pinheiro (2012) observaram que as modificações impressas no entorno da lagoa acarretam as transformações da paisagem e comprometem a qualidade ambiental, assim como no rio Piranhas, onde ocorre o desequilíbrio ecológico na área.

O ponto 3 apresentou uma maior faixa de vegetação, entretanto próximo aos pontos de amostragem, foi observado o cultivo de Copernicia prunifera (Mill.) H.E.Moore (Carnaúba) dentro da APP, fator determinante no processo de degradação ambiental, pois os agricultores utilizam as matas ciliares para o cultivo de milho, banana, feijão, entre outros, por serem naturalmente úmidas e favorecerem o desenvolvimento dessas atividades, fazendo com que as espécies nativas sejam removidas para o cultivo destas.

Uma grande dificuldade é encontrada na presença de agricultura próxima aos cursos d'água, onde ocorre o escoamento de fertilizantes e agrotóxicos, o que aumenta a contaminação das águas e eutrofização dos ambientes aquáticos, fazendo com que diminua a qualidade das águas dos rios (Siqueira et al., 2018).

Segundo Valle Junior et al. (2011), as grandes atividades agropecuárias quando associadas às queimadas e à exploração florestal, são consideradas os principais agentes causadores da degradação e perturbação em ecossistemas de bacias hidrográficas.

No ponto 4, foram observadas muitas espécies frutíferas, as quais foram introduzidas pelos moradores da região, visto o que foi relatado pelos mesmos, além das atividades de pesca e lazer no período chuvoso.

Tais ações interferem nos processos ecológicos da área, uma vez que, por exemplo, retirando-se a vegetação nativa e introduzindo outras espécies como a Spondias mombin L. (Cajarana), há a tendência de uma nova organização da fauna e flora (Araújo, 2018).

Santos, Pessi e Loverde-Oliveira (2018) destacam que a introdução de espécies por ação antrópica é uma grande ameaça à diversidade biológica, resultado encontrado também em seu estudo, podendo ocorrer a perda de habitat, de grande importância para os fragmentos florestais. Para que isso não ocorra, seus componentes (ecossistema, comunidade e espécie) devem estar em boas condições. 
Figura 6 - Agrupamentos das localizações dos pontos em época de estiagem. Paraíba. 2021.
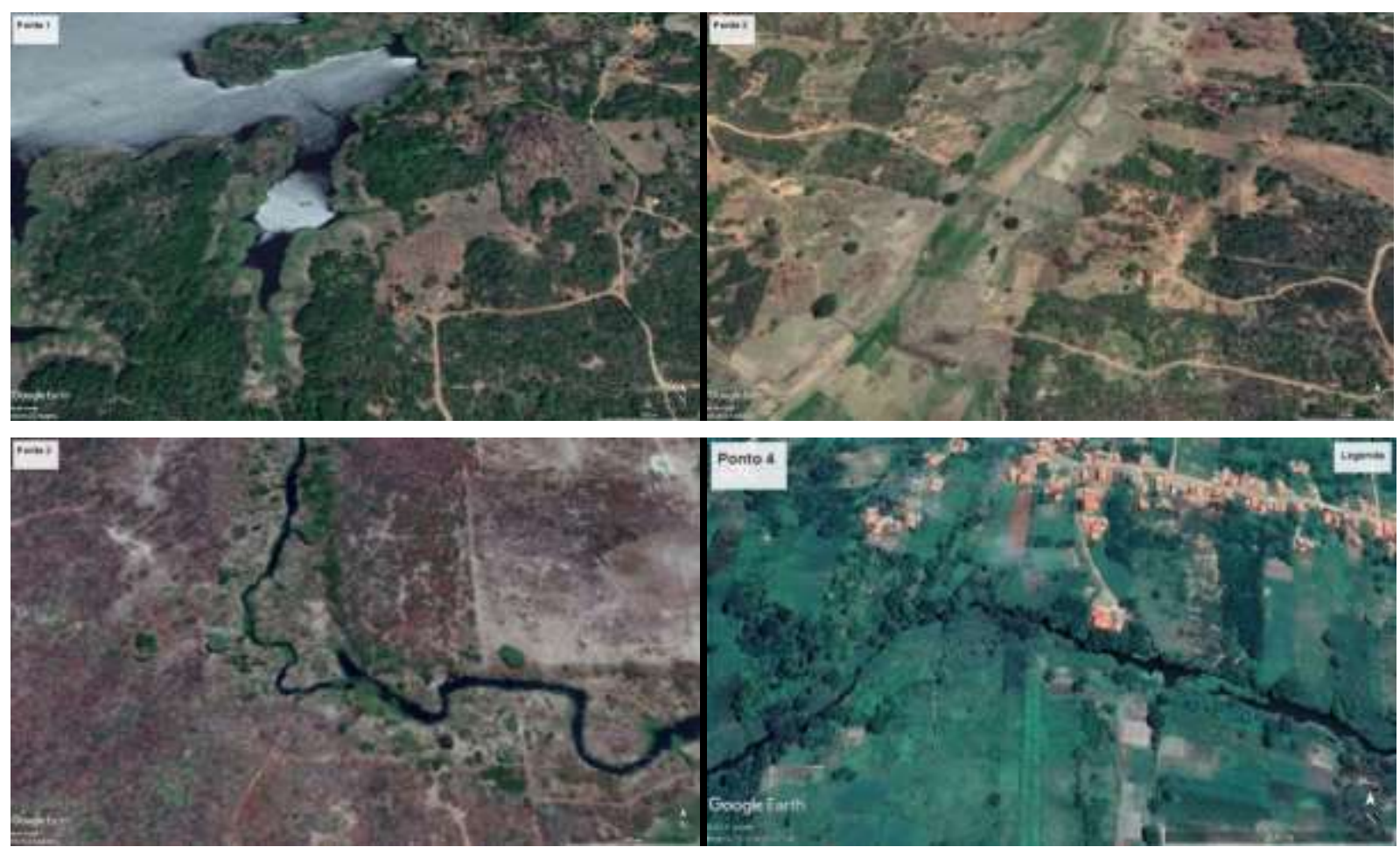

Fonte: Google Earth (2021).

A Figura 6 representa as áreas no momento de estiagem, com pouca vegetação e áreas com muito solo exposto. Destacase o ponto 3 , onde se verifica a diferença no porte da vegetação.

\section{Considerações Finais}

A delimitação do trecho estudado da mata ciliar do rio Piranhas mostra que há áreas com uma grande perturbação causada por ações antrópicas, entretanto há áreas com vegetação densa nas APP’s. Na questão das áreas antropizadas, há uma contradição quando comparado ao código florestal, que determina que essas faixas de proteção não deveriam estar com esses níveis de degradação ambiental.

Foi exposto que o cultivo e pastagens são as formas de utilização da terra que mais caracterizam o uso inadequado da área que é considerada como faixa de proteção e que o seu uso incorreto representa uma ameaça à conservação dos recursos naturais desta região.

Existem conflitos entre o uso e ocupação das áreas e a necessidade de proteção das Área de Preservação Permanente do rio Piranhas, no trecho estudado. Com o auxílio de técnicas de geoprocessamento, possibilitou-se a identificação e verificação dos níveis de ocupação na APP provocados pelas modificações na paisagem.

Sendo vista a importância deste tema nesta região, torna-se necessário o desenvolvimento de novos estudos mais profundos nas áreas de preservação permanente visto que elas possuem grande diversidade de espécies como também a construção e disponibilização de ferramentas importantes para o manejo, caracterização, uso e ocupação do solo.

\section{Referências}

Alvares, C. A., Stape, J. L., Sentelhas, P. C., Gonçalves, J. L. de M. \& Sparovek, G. (2014). Köppen's climate classification map for Brazil. Meteorologische Zeitschrift, 22, 711-728.

ANA - Agência Nacional de Águas (2019). Plano de recursos hídricos da bacia hidrográfica do rio Piancó-Piranhas-Açu. Brasília: ANA. 
Araújo, J. K. P., Santos, D.S., Bezerra, R. N. O., Araújo, J. S. O., Brito, M. S., Barbosa, F. M., Gomes, A. C., Macedo, R. O. \& Lacerda, A.V. (2018). Estrutura e padrões de distribuição espacial de Anadenanthera colubrina (Vell.) Brenan (Fabales:Fabaceae) presente no estrato regenerante em área de mata ciliar no Cariri Ocidental Paraibano. Revista Brasileira de Gestão Ambiental e Sustentabilidade, 5(9), 231-238. https://docs.google.com/viewerng/viewer?url=http://revista.ecogestaobrasil.net/v5n9/v05n09a14.pdf\&hl=pt_BR

Araujo, J. S. O. (2018). Análise do Componente Arbustivo-arbóreo regenerante em área de mata ciliar degradada no Cariri Paraibano. Sumé: Universidade Federal de Campina Grande.

Brasil. (1997). Lei 9.433 de 08 de janeiro de 1997. Política Nacional de Recursos Hídricos. http://www.planalto.gov.br/ccivil_03/Leis/L9433.htm..

Brasil. (2012). Lei $n^{o}$ 12.651, de 25 de maio de 2012. Novo Código Florestal Brasileiro. http://www.planalto.gov.br/ccivil_03/_ato20112014/2012/lei/112651.htm

Calheiros, R. O., Tabai, F. C. V., Bosquilia, S. V. \& Calamari, M. (2004). Preservação e recuperação das nascentes (de água e de vida). Piracicaba: Comitê das Bacias Hidrográficas dos Rios Piracicaba, Capivarí e Jundiaí - CTRN.

Farias, S. R. A. (2004). Operação integrada dos reservatórios Engenheiro Ávidos e São Gonçalo. Campina Grande: Universidade Federal de Campina Grande

Haas, A., Conceição, S. R., Descovi Filho, L. \& Henkes, J.A. (2018). Delimitação e caracterização de app através do uso de um sistema de informação geográfica (SIG): o caso das app's nos cursos de água da sub-bacia do lajeado pardo, noroeste do RS. R. gest. sust. ambient., 7(3), 640-649. https://www.researchgate.net/profile/leonidas_filho2/publication/329454195_delimitacao_e_caracterizacao_de_app_atraves_do_uso_de_um_sistema_de_infor macao_geografica_sig_o_caso_das_app's_nos_cursos_de_agua_da_sub-

bacia_do_lajeado_pardo_noroeste_do_rs/links/5c09b673299bf139c74463be/delimitacao-e-caracterizacao-de-app-atraves-do-uso-de-um-sistema-deinformacao-geografica-sig-o-caso-das-apps-nos-cursos-de-agua-da-sub-bacia-do-lajeado-pardo-noroeste-do-rs.pdf

Jensen, J. R. (2009). Sensoriamento Remoto do Ambiente: Uma perspectiva sobre recursos terrestres. São José dos Campos, SP: Parêntese.

Lima, J. R., Barbosa, M. P. \& Dantas Neto, J. (1998). Avaliação do incremento de açudes e sua relação com o uso do solo, através do uso de imagens TM/Landsat5: Estudo de Caso. Revista Brasileira de Engenharia Agrícola e Ambiental, 2(2), 243-245. http://www.scielo.br/pdf/rbeaa/v2n2/1415-4366-rbeaa-02-020243.pdf.

Macedo, H. P. (2014). Uma nova agenda para o semiárido do Nordeste. Rio de Janeiro: Banco Nacional de Desenvolvimento Econômico e Social.

Melo Filho, V. C., Vieira, A. S., Medeiros, A. C., Moreira, A. R. \& Maracaja, P. B. (2019). Análise da pegada hídrica no perímetro irrigado de São Gonçalo, localizado no sertão paraibano. GAS - Grupo de Gestão Ambiental no Semiárido, 1(1), 14-24. http://150.165.111.246/revistaccjs/index.php/rima/article/view/4/3.

Mendes, A. T. (2018). Delimitação da bacia hidrográfica do Rio Santo Antônio pela ferramenta de delimitação automática TauDEM. Revista Brasileira de Geografia Física, 11 (3). https://periodicos.ufpe.br/revistas/rbgfe/article/view/234278/30098

Mendes, I. L. F., Reis Filho, A. A. \& Espindola, G. M. (2019). Uso do SIG na delimitação e mapeamento das áreas de preservação permanente do rio Poti (Teresina/PI). Braz. J. of Develop. 5(1), 864-875. http://www.brjd.com.br/index.php/BRJD/article/view/1030/900.

Mesquita, E. A., Cruz, M. L. B. \& Pinheiro, L. R. O. (2012). Geoprocessamento aplicado ao mapeamento das formas de uso da terra na área de preservação permanente (APP) da Lagoa do Uruaú - Beberibe/CE. Revista Geonorte, 2(4), 1509-1518. https://www.periodicos.ufam.edu.br/index.php/revistageonorte/article/view/2238/2081

Nascimento, A. P. P. (2018). Analise multitemporal das matas ciliares do município de ipanguaçu-rn pelo uso do processamento digital de imagens. Natal: Instituto Federal de Educação, Ciência e Tecnologia do Rio Grande do Norte.

Oliveira, T. H., Machado, C. C. C., Silva, J. S., Galvincio, J. D., Pimentel, R. M. M. \& Silva, B. B. (2010). Índice de Umidade (NDWI) e Análise EspaçoTemporal do Albedo da Superfície da Bacia Hidrográfica do Rio Moxotó-PE. Revista Brasileira de Geografia Física, 3, 55-69. doi: https://doi.org/10.26848/rbgf.v3i2.232669

Santos, J. W. M. C., Pessi, D. D. \& Loverde-Oliveira, S.M. (2018). Caracterização da flora arbórea na mata ciliar do córrego Arareau no perímetro urbano de Rondonópolis (Mato Grosso). Biodiversidade, 17(1), 127-142. http://www.periodicoscientificos.ufmt.br/ojs/index.php/biodiversidade/article/view/6542/4259.

Silva, B. B., Braga, A. C. \& Braga, C. C. (2011). Balanço de radiação no perímetro irrigado São Gonçalo-PB mediante imagens orbitais. Revista Caatinga, 24(3), 145-152. https://periodicos.ufersa.edu.br/index.php/caatinga/article/view/2282/4764.

Silva, B. B., Galvincio, J. D., Montenegro, S. M. G. L., Machado, C. C. C., Oliveira, L. M. M. O. \& Moura, M. S. B. (2013). Determinação por sensoriamento remoto da produtividade primária bruta do perímetro irrigado São Gonçalo-PB. Revista Brasileira de Meteorologia, 28(1), 57-64. https://pdfs.semanticscholar.org/af26/49808d00bc0302e9fadffd835acea3a96f27.pdf?_ga=2.191367210.1628534387.1631571702-1677368277.1631571702.

Silva, T. C., Ramos, M. A., Alvarez, I. A., Kill, L. H. P. \& Albuquerque, U. P. (2011). Representações dos proprietários e funcionários de fazendas sobre as mudanças e conservação da vegetação ciliar às margens do rio São Francisco, Nordeste do Brasil. Sitientibus série Ciências Biológicas, 11(2), 279-285. https://ainfo.cnptia.embrapa.br/digital/bitstream/item/58191/1/Artigo-Kiill.pdf.

Siqueira, E. C., Silva, S. N., Lopes, F. G., Andrade, F. E. \& Braga, C. F. (2018). Avaliação dos impactos da seca no perímetro irrigado de são Gonçalo-PB. Revista Principia, 40, 21-27. http://periodicos.ifpb.edu.br/index.php/principia/article/viewFile/1285/860.

U.S.G.S. Department of the Interior. U.S. Geological Survey. https://earthexplorer.usgs.gov

Valle Junior, R. F., Val, B. H. P., Carmo, D. A., Souza, M. A. S. C. \& Abdala, V. L. (2011). Diagnóstico das áreas de preservação permanente na microbacia hidrográfica do córrego Jataí. Revista Caatinga, 24(3), 153-157. https://periodicos.ufersa.edu.br/index.php/caatinga/article/view/1965/4749. 
Research, Society and Development, v. 10, n. 12, e121101220138, 2021

(CC BY 4.0) | ISSN 2525-3409 | DOI: http://dx.doi.org/10.33448/rsd-v10i12.20138

Victoria, D. C., Hott, M. C. \& Miranda, E. E. (2008). Delimitação de áreas de preservação permanente em topos de morros para o território Brasileiro. Revista Geográfica Acadêmica, 2(2) 66-72. https://www.alice.cnptia.embrapa.br/alice/bitstream/doc/17750/1/2203.pdf

Zakia, M. J. B., Ferraz, F. F. B, Righeto, A. M. \& Lima, W. P. (2009). Delimitação da zona ripária em uma microbacia. Revista Agrogeoambiental, 1(1), 51-61. 